\title{
Upholding Core Socialist Values and Improving the Charity Governance Mechanism
}

\author{
Meiling Liu ${ }^{1}$, Fushuai Pang ${ }^{1}$, Gefei Liu \\ ${ }^{1}$ School of Marxism, Shanxi University, Taiyuan, Shanxi 030006, China \\ ${ }^{2}$ Faculty of Arts, Communication University of Zhejiang, Hangzhou, 310018, China
}

\begin{abstract}
Charity governance mechanism is the internal connection and operation mode formed by the organic combination of various elements in the implementation of the charity management system. It is the key to improve the efficiency and effectiveness of the charity governance by taking advantage of charity management's institutional strengths. At present, Charity in our country is vigorous and the charity management system is becoming more and more perfect. However, the charity governance mechanism is still imperfect, which hinders the development of charity. We must uphold core socialist values, establish an emergency mechanism for charity governance, build a cooperation mechanism for charity governance and improve the supervision mechanism of charity governance to improve the charity governance mechanism and continue to modernize the national governance system and capacity.
\end{abstract}

Keywords: Core socialist values, Charity governance mechanism, Emergency mechanism, Cooperation mechanism, Supervision mechanism.

\section{Establishing an Emergency Mechanism for Charity Governance}

To do rescue and relief work and deal with emergencies are one of the main tasks of charity activities. However, emergencies have the characteristics of suddenness, uncertainty, destructiveness and seriousness, which are relatively difficult to deal with. As the major participants in charitable activities, charity organizations "participate in emergency management can effectively compensate for government forces and improve the efficiency of emergency response."[1] After the outbreak of the COVID-19 epidemic, the charity organizations made important contributions to the fight against the epidemic, but they also exposed some shortcomings of participating in emergency management, such as low allocation efficiency; low transparency of material flow; and the number of donated goods is not disclosed in time, etc. Therefore, we must adhere to the guidance of the core socialist values and establish the emergency mechanism of charity governance to support the development of charity organizations and play their leading and coordinating role preferably.

\subsection{Enhancing the CPC Leadership Effectively}

Only by doing the top-level design can we better integrate charity resources and achieve precise docking. To deal with emergencies, the first is that we must improve the emergency command mechanism of the CPC leadership in emergencies and ensure that the CPC plays its role as the core leadership in the course of exercising overall leadership and coordinating efforts from all concerned. Secondly, Party and government officials at all levels must take the initiative and play a key role. And they must have strong capabilities in crisis management and an acute sense of danger and risks. The third is to give full play to the role of Party branches in fighting emergencies and improve the ability to deal with natural disasters and emergencies continuously. The fourth is to give full play to the exemplary vanguard role of Party members in the emergency response work of charity governance, and encourage Party members to rise up to the challenge and respond to it bravely.

\subsection{To Clarify the Responsibilities of All Parties}

Only a clear division of labor and specific responsibility can help to play the main role of all parties and better respond to emergencies in charity governance. As the management department of charity organizations, the government should coordinate and unite all parties to help build a national emergency platform. As an important main body of charity work, charity organizations must do a good job in mobilizing social forces, as well as raising, counting, transferring, and distributing emergency supplies. Volunteers should continuously improve their own quality and emergency response capabilities, and actively participate in emergency rescue work. Enterprises are the largest main body of material donations, should actively undertake social responsibility and participate in donation and dedication at the first time. The people are the main force in charity governance, and they must give full play to their main role in emergency management and respond to the call for donations.

\subsection{Establishing an Information Sharing and Management Platform}

Only through the national charity information sharing and management platform, we can timely publish disaster statistics, material assistance, donations and use of information, and implement digital dynamic management so that people can grasp the dynamics and judge the situation in a timely manner. Help seekers should announce the supply and demand status of materials in a timely manner, so that donors can donate materials accurately and timely, and charity organizations allocate materials in a timely manner. Donors should make donations with a full understanding of actual needs, and avoid giving blindly. As an important link and bridge connecting donors and beneficiaries, charity organizations should not only provide reasonable guidance to donors, but also timely understand the actual needs of all parties and allocate materials. The establishment of the information platform can effectively promote the openness, detail, and transparency of information, supervise charity organizations to make their work more perfect, and promote 
the legal and reasonable use of materials.

\subsection{Charity Organizations Must Establish Emergency Plans}

Only if charity organizations have the ability to deal with emergencies, the public will trust them more and their charity governance capabilities will gradually improve. A set of scientific and standardized emergency plans can effectively improve the ability of charity organizations to deal with unexpected events. When a charitable organization forms an emergency plan, it is necessary to clarify the members of the leadership team and their functions, the part of the organization's work, and the specific operation plan in case of emergencies. In addition, for problems that arise in the emergency process, accountability should be held after the event to ensure that the responsibility is specific to the individual, which can enhance the sense of responsibility and mission of charitable organization members.

\subsection{Establishing a Material Reserve and Resource Scheduling Mechanism}

At present, the management ability and specialization level of material reserves and resource scheduling of charity organizations are low. They cannot properly count and arrange donated materials, nor can they coordinate the use of materials and the supply and demand of materials. In addition, the limited logistics ability of charity organizations leads to a large number of material hoarding, which is difficult to allocate and distribute materials efficiently. For this, our country should establish a charity material reserve and resource scheduling mechanism, and establish a nationwide fundraising material storage and dispatch center and a fundraising material reserve storehouse in provinces, cities and key areas to provide material reserves and resource scheduling. In addition, charity organizations should cooperate with professional logistics teams and adopt professional logistics teams to manage donated materials, and efficiently complete the donated materials storage, inventory management, allocation and distribution, so as to improve the logistics management level of charity organizations.

\section{Building a Cooperation Mechanism for Charity Governance}

Charity governance requires the cooperation of all social forces, but the social forces are extensive and have their own characteristics. Only by mutual cooperation can they give full play to their due synergy. Therefore, it is necessary to build a cooperation mechanism for charity governance, which is not only an inevitable requirement for the modernization of charity governance, but also an inevitable requirement for building a new pattern of charity governance. Promoting the construction of a cooperation mechanism for charity governance should be carried out from the following aspects.

\subsection{Giving Full Play to the Leading Role of the Government}

In our country, charity is developed under the leadership of the government. To build a cooperation mechanism for charity governance should also play the leading role of the government. First, to clarify the relationship between charity organizations and the government. Government plays a leading role in the development of modern philanthropy, managing charity organizations and charitable activities. charity organizations are an important subject of philanthropy. Modern philanthropy mainly relies on charity organizations to complete charitable activities, including raising funds, selecting projects, organizing activities, public accounting, and effect evaluation, etc. The second is to give play to the leading role of the government. Due to the dual reasons of history and reality, the government has always played a leading role in the development of philanthropy. Therefore, we must continue to play the important role of the government in guiding and coordinating all parties in the process of building a collaborative mechanism for charity governance. The third is to always adhere to the principle of taking the interests of the people above everything else. Our people are makers of history and also the makers of the charity governance synergy mechanism. When the government organizes charitable activities, it must always safeguard the interests of the people and give play to the wisdom and strength of the people.

\subsection{Adhering to the Correct Concept of Cooperation}

Charity governance is systemic and complex, which requires all parties to charity to adhere to the correct concept of cooperation in the construction of charity governance synergy mechanism. The first is to uphold core socialist values. The core socialist values are the primary principles and correct concepts that we must adhere to in the construction of the charity governance cooperation mechanism. The core socialist values must be integrated and reflected in the whole process and all links of the construction of the collaborative mechanism. The second is to bring out the spirit of the host and to make an active contribution. The CPC, government, social organizations, and citizens are all main subjects of charity governance. In the process of charity governance, they must give full play to the spirit of masters, strengthen the awareness of collaborative cooperation, strengthen the concept of cooperation, and sincerely unite and play a role. The third is to clarify responsibilities. One of the important contents of solving the responsibility problem is to make the responsibility clear and concrete. Charity governance is jointly participated by multiple subjects, which requires that the governance parties have clear responsibilities, perform their duties, and collaborate with each other. The government should support policy and be a service-oriented government. Social organizations should play their roles and serve the society. The public should actively participate and be willing to contribute. In this way, the charity governance system can be formed and gradually modernized.

\subsection{Strengthening the Construction of Charity Organizations}

In the process of charity governance, charity organizations are the main body, a bridge between the government and the people, and play an important role. To improve charity governance, it is necessary to strengthen the construction of 
charity organizations. First, to increase policy support and actively promote the construction of charity organizations. Proactively cultivate charity organizations by appropriately relaxing the entry barriers for charity organizations, increasing tax incentives, increasing financial support, and other measures. In particular, it is necessary to cultivate social service, social urgently needed, and community service charity organizations. Second, charity organizations should strengthen their own capacity building. Charity organizations must always adhere to the core socialist values, improve the organizational system and organizational culture, and increase the credibility of charity organizations. The third is to improve laws and regulations to provide legal protection. Taking The Charity Law of the People's Republic of China as the core and foundation, further improve laws and regulations to provide institutional guarantees for the healthy and orderly development of charity organizations. Charity organizations must abide by laws and regulations, exercise their rights and assume obligations within the scope of the law, and regulate their own behavior.

\section{Improving the Supervision Mechanism of Charity Governance}

President Xi Jinping said that "charity organizations and the Red Cross should operate efficiently, increase transparency and take the initiative to be supervised, so that every love and goodwill can be implemented in a timely manner."'[2] The promulgation of The Charity Law of the People's Republic of China has led charity to the path of standardization and legalization. However, in the actual development of charitable activities, charity still faces the problem of inadequate supervision. Therefore, we must adhere to the core socialist values and improve the supervision mechanism of charity governance.

\subsection{Strengthening Internal Supervision of Charity Organizations}

The internal supervision institutions of charity organizations mainly include the board of supervisors and the board of directors. The charity organization should clarify the purpose and specific functions of the establishment of the two, specify the rights and obligations of the board of directors and the board of supervisors in the form of documents, establish a sound self-monitoring system, and improve self-monitoring capabilities. The board of directors and the board of supervisors should also supervise and manage the project operation, financial status, use of funds, and administrative operations of charity organizations in accordance with laws and regulations, so as to ensure that they are not absent and offside and give full play to their own functions.

\subsection{Strengthening Government Supervision}

The supervision of government mainly includes the supervision of the civil affairs department and the financial department, the audit department, the taxation department and other business authorities. All functional departments should clarify the scope and responsibilities of charity supervision, and avoid irresponsible phenomenon due to multiple supervision. The government should carry out daily supervision of the information disclosure status, property management status and project development status of charity organizations, and set up a special supervision team for major charity projects. The government should timely investigate and punish the illegal behavior of charity organizations, and guide the legal operation of charity organizations. At the same time, the investigation and supervision should be made public in a timely manner, so that the public can understand the operation status of charity organizations timely, and promote the healthy development of charitable organizations.

\subsection{Improving the Supervision of the Charity Industry}

The charity industry should set up special industry associations and federations to formulate industry norms and ethics that they abide by. The content should include abiding by the Constitution, laws and regulations, promoting and practicing the core socialist values, observing professional ethics, and undertaking social responsibilities. By strengthening industry supervision, on the one hand to regulate and restrict the charity industry, on the other hand, it promotes healthy competition in the charity industry. In addition, those so-called "charity organizations" and "charitable activities" that violate the core socialist values must be criticized and terminated in a timely manner, so as to restrict and standardize charity organizations while improving the credibility of the charity industry.

\subsection{Establishing a Third-Party Regulatory Agency}

It is necessary to establish an authoritative and specialized third-party charity supervision institution, which is supervised by the government but is independent of the government. According to relevant charity laws and regulations, the specific supervision scope of charity supervision and management institutions shall be divided, the specific responsibilities and supervision measures shall be clarified, and charity supervision and management shall be carried out in an objective and fair manner. On the one hand, the third-party regulatory agencies use their professional advantages to conduct a scientific evaluation of the transparency and operation of charity organizations based on extensive investigations of charity organizations, so that the public has a clear understanding of the status of charity organizations. On the other hand, charity organizations can understand their own problems through the big data analysis and technical support of independent third-party organizations, make timely improvements and self-improvements, so as to better fulfill their mission and social responsibilities.

\subsection{To Improve the Social Supervision System}

Social supervision is the most extensive method of supervision, and it is an indispensable and important part of the charity governance supervision mechanism. The first is to strengthen media supervision. Media supervision has the characteristics of timeliness, comprehensiveness, great influence, and fast dissemination. It is necessary to fully mobilize the supervision enthusiasm of newspapers, magazines, radio and television and other media. At the same time, it is necessary to give full play to the important role of 
platforms such as Weibo, WeChat and Tik Tok in social supervision. Once it is discovered that charity organizations have illegal activities, they must be exposed and criticized in time, and supervised effectively. The second is to strengthen public supervision. The public plays an important role in the supervision work, and we must attach importance to the people's enthusiasm and fighting spirit for supervision. We must establish and improve a mechanism for the public to participate in the supervision of charity governance, give full play to the spirit of public ownership, and actively assume the responsibilities and obligations of charity supervision through public opinion.

In short, the governance in the field of charity requires mutual cooperation among multiple entities, smooth and convenient information exchange, and constant supervision of all parties. Only in this way can we improve the charity governance mechanism and promote the sound development of charity.

\section{Acknowledgement}

This paper is supported by the fund: National Philosophy and Social Science Foundation Project "Research on Charity Ethics Guided by Socialist Core Values", project number: $15 \mathrm{BKS} 104$.

\section{References}

[1] Shao Peizhang, Liang Meiying. Countermeasures and suggestions for charity organizations to participate in the emergency management of the epidemic[N]. China Social Press, 2020-02-24 (006).

[2] Xi Jinping. Speaking to the meeting held to coordinate epidemic prevention and control and economic and social development[N]. People's Daily, 2020-02-24(002).

\section{Author Profile}

Meiling Liu (1971-), female, Ph.D. Professor, School of Marxism, Shanxi University, Secretary-General of Shanxi Provincial Ethics Society.

Fushuai Pang (1996-), male, is a Master Degree candidate at the School of Marxism, Shanxi University, and has been studying for a Master's degree since 2018.

Gefei Liu, born in 1996, graduated from Faculty of Arts, Communication University of Zhejiang. 